\title{
Individual Differences in First and Fourth Year College Women’s Short Term Mating Strategy Preferences and Perceptions
}

\author{
Margaret J. Cohen, T. Joel Wade \\ Department of Psychology, Bucknell University, Pennsylvania, USA \\ Email: t.joel.wade@bucknell.edu
}

Received July 19 ${ }^{\text {th }}$, 2012; revised August 21 ${ }^{\text {st }}, 2012$; accepted September $22^{\text {nd }}, 2012$

\begin{abstract}
Using survey methodology, a cross sectional study was undertaken to ascertain whether first and fourth year college women have different perceptions and behavior associated with short term mating preferences. It was hypothesized that after incurring significant negative or costly experiences associated with hooking up, fourth year women would prefer men who had qualities associated with a desired long term partner as opposed to characteristics associated with short term mating partners. The results were partially consistent with the hypothesis. Reported preferences in a desired partner and perspective on hooking up differ between first and fourth year groups. No difference was found between frequency and willingness to hookup between the two groups. The findings are explained in terms of evolutionary theory, social exchange theory, and sexual script concepts.
\end{abstract}

Keywords: Mating Strategy; Preferences; Mating Costs

\section{Introduction}

The psychological study of attraction and sexual behavior is a complex and dynamic field. Examining various theoretical approaches to explain one particular phenomenon creates a holistic and inclusive framework for understanding the behavior. This research seeks to examine if and why a difference may exist in sexual behavior and preferences among traditionally aged eighteen-year old first and traditionally aged twenty-one year old fourth year college women, a topic not examined in prior research. An evolutionary perspective was used to discuss traditional female sexual preferences and mating tactics and social exchange theory was utilized to explore differences that may exist among women in the same environment. Additionally, sexual script concepts were utilized to illuminate cultural norms, particularly the college hookup culture, and the impact the social environment has in shaping behavior.

\section{Evolutionary Theory}

Looking through the lenses of evolutionary theory, sexual preferences and behaviors are remnants of the history of the human species. Charles Darwin stated that the key to evolutionary change over time was natural selection; behaviors that were advantageous to the survival of a species were passed on from one generation to the next (Buss, 1998). This theory was expanded to include traits that differ among the sexes when Darwin proposed his theory of Sexual Selection. This theory suggested that specific male and female characteristics that were successful in attracting a mate would be passed down through generations (Buss, 1998).

Historically, men look to secure a short term female partner who is fertile and sexually accessible while minimizing commitment and investment. In contrast, men have looked to secure a long term female who is reproductively valuable with good genes, but would also be a good mother and wife. Women seek men with external resources that they can secure for themselves or their offspring and good genes. They utilize short term mating to secure immediate resources or to assess whether the man would be a suitable potential long term mate (Buss \& Schmitt, 1993). Humans secure a desired mate by utilizing sexual strategies which differ by sex (Gangestad \& Simpson, 2000). The term strategy implies goal directed behavior through which humans attempt to solve adaptive problems by seeking mates that would have been advantageous to their ancestors in evolutionary history (Buss \& Schmitt, 1993). In 1972, Robert Trivers suggested that the more parentally invested sex had to be choosier in mate selection. The inherent difference between men and women, the fact that women get pregnant, and men do not, suggests that the woman has more to lose; therefore, she must be the choosier sex (Buss, 1998).

Sexual strategies are considered universal characteristics and allow the scholar to understand "typical” and "a-typical” male and female behavior. Humans are said to be unaware of such strategies, which are evolved solutions employed to solve adaptive problems (Buss \& Schmitt, 1993). These behavioral materializations of adaptive psychological functions are activated in specific temporal contexts which create cross cultural differences (Buss \& Schmitt, 1993). These differences are the result of the human brain having evolved the ability to adjust to specific conditions (Gangestad \& Simpson, 2000).

Evolutionary theory emphasizes the way in which sexual adaptations maximize genetic fitness, which is the ability of the human being to survive and reproduce offspring that will survive. The theory does not adequately explain differences within various contexts (Kenrick, Groth, Trost, \& Sadalla, 1993). Why, for example, would two women in the same context prefer and pursue different men and different outcomes? An alternate the- 
ory of male-female relations may be able to answer to this question.

\section{Social Exchange Theory}

Social exchange theory is an alternate approach to understanding sexual behavior and can explain differences within the female species. In 1958, George Homans introduced the idea that interactions among individuals can be viewed as an economic exchange of both material and non-material goods (Homans 1958; Emerson, 1976). Elements of human behavior are governed by the success proposition, i.e., the more a person is rewarded for certain behavior the more likely they are to perform that behavior (Emerson, 1976). The exchange occurs when the outcome, or profit, is considered more valuable than the cost of the behavior. The degree of the reward dictates the value of the behavior, simply, "profit = reward-cost" (Homans, 1958).

The value proposition explains change in behavior as a result of change in perceived value of the outcome. When the individual feels the profit is no longer valuable, the individual will alter the behavior and the behavior will diminish (Homans, 1958). The more a reward is valued, the more the individual will produce the behavior. Through the lens of social exchange theory, choices individuals make when pursing a mate are attempts to maximize gains and minimize losses, suggesting that men and women seek sexual interactions where the benefits of involvement outweigh the costs.

Social exchange theory accounts for individual differences and changes in behavior, and the evolutionary approach describes universal preferences. However, these evolutionary and economic models do not encompass a culturally relevant explanation to account for the trends in sexual behavior observed on the modern college campus (Kenrick et al., 1993).

\section{Sexual Scripts}

While theoretical frameworks provide insight into sexual behavior, the environment in which men and women interact is powerful in shaping the perceptions and cognitions of individuals. Sociologists William Simon and John H. Gagnon (1968) have influenced the area of cognitive psychology through their research on the sexual script (Simon \& Gagnon, 2003). Cognitive psychology investigates processes of thought and often focuses on schemata, abstract structures of knowledge (Abelson, 1981). One type of schema is called a script, which is a cognitive representation of ritualized, sequential events. Schemas are triggered under environmental conditions and organize thoughts and expectations about the appropriate sequence and proper conduct expected in to occur in those situations (Abelson, 1981).

When individuals interact with one another they often follow the cultural "protocol" and invoke the stereotypical norms that exist within that society. The backbone of script theory is that individuals are influenced by the cultural messages available to them. They internalize cultural scripts and the scripts become part of the individual's cognitions, influencing perceptions and consequently, behavior. Sexual scripts are specific to gender and culture and often define or limit what is seen as appropriate for men and women in sexual interactions (Frith \& Kitzinger, 2001). Simon and Gagnon maintain that because sexual behavior and conduct is located in the social realm, it has been so- cially produced and maintained (Simon \& Gagnon, 2003). Culture organizes the way individuals behave and perceive sexuality. The context or environment is the stage through which men and women play out various cognitive and behavioral mechanisms and provides a lens through which sexual strategies and cost-benefit analysis occur.

\section{Integrating Theories}

Evolutionary theory, social exchange theory, and cultural scripts all contribute to understanding sexual preferences and behavior among college women. These theories can be employed to explain qualities women desire in a mate, the costs and benefits they associate with sexual interactions, and the way their preferences play out in the social realm of the college campus.

According to Buss and Schmitt (1993), women use short term mating to evaluate men as potential long term mates. Whereas women typically seek commitment, in an environment where a man is not willing to commit, women will seek quailties that are indicative of good genes (Gangestad \& Simpson, 2000). Greater importance is placed on physical attractiveness when evaluating men in a short term mating context (Gangestad \& Simpson, 2000). Past research has even suggested that more symmetrical men are preferred as short term mates (Gangestad \& Simpson, 2000). If women cannot secure attractive men as long term mates, it would be adaptive to pursue an attractive short term mate. This is considered "good gene sexual selection" which is a controversial topic among evolutionary theorists today, but implies that in favoring physically attractive short term mates, women attempt to secure good genes that could be passed on to potential offspring, increasing the likelihood of survival (Gangestad \& Simpson, 2000; Buss \& Schmitt, 1993).

Through evolutionary history, females used short term mating for immediate extraction of resources such as food or protection and therefore favored observational cues such as ambition and status (Buss \& Schmitt, 1993). Men who can provide access to resources are universally favored among women, but culture determines which resources are considered valuable (Gangestad \& Simpson, 2000). Eagly and Wood (1999) found that various resources are included in a "gender empowerment measure". Examples of valued resources include monetary success or social influence (Gangestad \& Simpson, 2000). Because valued resources and status are culturally defined, it is imperative to understand how such adaptations play out on an American college campus where short term dating is the norm (Flack, Daubman, Caron, Asadorian, D’Aureli, Hall, Gigliotti, Michener, \& Wheeler, 2007).

\section{Hooking Up}

The casual sexual encounters known as "hook-ups" have replaced traditional dating norms on college campuses across the United States. Hooking up is a seemingly casual sexual encounter between two individuals. The hookup can occur on one single occasion or occur repeatedly for an extended period of time. The individuals may be strangers, acquaintances, or friends, but have no exclusive obligation toward one another. Some physical interaction is typical, such as kissing, but may or may not include sexual intercourse (Garcia \& Reiber, 2008; Flack et al., 2007). 
The Institute for American Values conducted an 18 month study on the attitudes and values of today's college women (Glenn \& Marquardt, 2002). The study was a nationally representative sample and revealed the broad and varied definition of hooking up. Noticeable differences were found in the way black and white women define hooking up, additionally norms and definitions of the term "hooking up" differed greatly on various campus environments. Despite these differences, three fourths of the respondents stated that the term hookup commonly describes a distinctive sexual-without-commitment interaction (Glenn \& Marquardt, 2002). The ambiguity of the term "hook up" contributes to its popularity given that women may attempt to avoid reputational damage because hooking up does not necessarily imply sexual intercourse (Bogle, 2008; Glenn \& Marquardt, 2002).

All campuses differ and cultural factors contribute to the proliferation of hook up behavior. Flack et al., (2007) revealed that, "cases in which the social scene on a small, relatively insulated campus is directed by a traditionally strong Greek system... [is] likely to produce conditions that are unfavorable to women" (Flack et al., 2007: p. 154). The presence of a strong Greek system on campus makes hooking up increasingly prevalent and places men in control when fraternities set the scene for gender relations on campus by dictating the atmosphere in which hookups occur (Boswell \& Spade, 1996). This phenomenon is intensified if men and women live and dine in separate quarters, creating an atmosphere where most socializing and sexual behavior occurs under the influence of alcohol, at night, and in a bar or at a fraternity house.

Historically, women incur various dangers when partaking in short term sexual strategies as opposed to long term mating contexts. There is a heightened risk of contracting sexually transmitted diseases and a greater risk of physical and sexual abuse (Buss \& Schmitt, 1993). Additionally, it is easy to acquire reputational damage to a desired long term mate through short term strategies. Through evolution, men seeking long term mates have come to disfavor cues that show women have multiple mates. Sexual promiscuity may be interpreted as a sign that a woman can't obtain a long term mate or is sexually accessible. For this reason, reputational damage is more severe for women than men because of paternity uncertainty (Buss \& Schmitt, 1993). Research on the hookup culture has demonstrated that hooking up increases the chances that a woman acquires a bad reputation or puts herself at risk for unwanted sex (Bogle, 2008; Flack et al., 2007).

Hooking up poses an emotional risk to college women, this can be intensified by the presence of fraternities or alcohol consumption on campus. Alcohol consumption intensifies attitudes and orientations toward rape culture and is often the major focus of social events on a college campus at either fraternity parties or campus bars (Boswell \& Spade, 1996). Boswell and Spade (1996) revealed that men had control on campus when fraternities determined the setting for male/female interaction. The degree of conformity is intensified in a Greek system because it solidifies in-group and out-group identity creating both "group-think syndrome" and an us/them atmosphere. Additionally, men said that they didn't hold negative attitudes toward women on an individual basis, but when they are together in groups they sensed peer pressure to be disrespectful toward women. Women were aware that the conditions on campus were not optimal; they reported feeling hurt or humiliated by men they were hooking up with, but continued to follow the hookup script while recognizing the injustices. If women are conscious of the costs associated with hooking up on the college campus, one must wonder what motivates the women to continue to partake in the culture.

\section{Motivations}

Preferences and ideals do not always dictate behavior and women often "track" their environment to determine which tactics may be beneficial to obtain a desired outcome (Gangestad \& Simpson, 2000). As described earlier, short term mating strategies can be utilized for more immediate access to resources. Thus, many women may use hooking up as a college sexual strategy and may use it as an attempt to enter a longterm relationship. From an evolutionary standpoint, if women want to enter monogamous relationships, and the only available avenue for doing so is by hooking up, because traditional dating does not occur, then women will partake in this cultural norm.

Garcia and Reiber (2008) surveyed 507 males and females undergraduates to answer questions regarding their motivations for hooking up and found that only six percent of the participants actually expected hookups to result in a traditional romantic relationship. So, the female behavior exhibited on the college campus may seem atypical and maladaptive because it would seem to diverge from the traditional female desire to pursue a long term relationship. However, upon further examination, it is clear that women included in Garcia and Reiber (2008) still want to enter long term monogamous relationships. One can see this exposed in the data through the discrepancy between expectations and ideal outcomes of a hookup. The largest proportion of women (43\%) hoped a traditional romantic relationship would result from a hookup, whereas only $8 \%$ actually expected this to occur (Garcia \& Reiber, 2008).

Hooking up can then be seen as a behavior consistent with the ability to alter sexual or survival tactics as a function of current environmental conditions as Crawford and Anderson, (1989) report. This alteration to a short term strategy is an adaptive function that can be explained through the concept of Darwinian algorithms, i.e., the human capability to make domain appropriate inferences that are adaptive to a particular social environment. These innate specialized learning mechanisms explain the way in which our judgments and choices are dictated by our ability to organize attention to what is appropriate and adaptive in a particular environment (Crawford \& Anderson, 1989). Thus, the mechanisms employed by the female college student should not be seen as constraints, but rather as enabling devices that can be categorized as pseudonormal behavior, or behavior that was ancestrally maladaptive, but is now currently acceptable and even adaptive. (Crawford \& Anderson, 1989).

Another more basic motivating factor for hooking up, that college women typically experience, is the desire to fit in. LaPlante, McCormick, and Brannigan's (1980) research indicated that students' actions during sexual behavior were dictated by the sexual script. Qualities such as individual personality characteristics and locus of control had little or no influence on the sexual interactions between men and women. A later study on sexual initiation in dating interactions (O’Sullivan \& Byers, 1992) confirmed that sexual scripts are the overriding influence on determining who initiates sexual activity.

The perceived norms about how men and women are supposed to interact are increasingly influential in the hookup cul- 
ture. Because hooking up is an ambiguous term, men and women are often unaware of the extent to which their peers are engaging in sexual behavior. Pluralistic ignorance makes perceived cultural norms and sexual scripts increasingly influential. Pluralistic ignorance (Allport, 1924) occurs when a person believes that their judgments or beliefs differ from what is normal and conform to what they believe is the more desirable or normative behavior. In an investigation of pluralistic ignorance and hooking up Lambert et al., (2003) revealed that pluralistic ignorance characterizes the attitude of college students. The study found that both men and women believed other members of their gender were more comfortable with hooking behaviors than they actually were. Because hooking up has become the norm, students on college campuses often engage in this behavior because they feel that others are more comfortable with the behavior than they really are (Bogle, 2008; Lambert et al., 2003).

\section{Age}

Conformity is one motivator associated with hooking up. Research in this area suggests that levels of conformity are dependent on age. Child development studies have found that from preadolescence to the adolescent period, conformity to social pressure increases. The period after adolescence, through early adulthood, is marked by a decrease in social conformity (Costanzo \& Shaw, 1966). These results may be applicable in the study of individual differences that predict sexual strategies. Buss and Schmitt found that short term mating is typically used to assess value in a potential mate and short term strategies are more frequently adopted by younger women. Increasing age brings about diminishing returns when the woman has already developed assessment functions and knows what she is looking for. Therefore, with age, we see a shift from short term to long term mating strategies (Buss \& Schmitt, 1993).

The possibility that women become less interested in short term strategies as they age was echoed in the Boswell and Spade study. Many women stated that after the first year of college they tire of the hook-up scene (Boswell \& Spade, 1996). With this information in mind, the present study sets out to determine whether or not college women in a hook-up culture alter their dating preferences in a manner consistent with the aforementioned theories.

In the college environment, it would be beneficial for the woman to adapt to her surroundings and alter her sexual strategy when a perceived reward is no longer valued. With this in mind, one can assume that among traditional-age college women, a fourth year college woman's sexual strategy would differ from a first year college woman's sexual strategy if there is a change in the degree of value of the reward generated by engaging in "hooking up" behavior. Specifically, following social exchange theory, fourth year women may feel that the sexual strategy they are using is no longer rewarding. However, first year women may feel their sexual strategy is rewarding because they have not experienced the same costs that fourth year women have experienced. The present study examines this.

\section{Focus of the Present Study}

The focus of the present research will be on whether or not there are differences in first and fourth year women's mate preferences and behaviors and perspectives using a cross-sec- tional design. When the social position of a female, her age, and her learned experiences change throughout college, these factors may alter her perspective on the value of certain rewards associated with the original behavior. According to social exchange theory, if the degree of value in the reward diminishes, the behavior will be diminished as well. Thus, the behavior of the first year student may differ from the behavior of the fourth year student because the fourth year student will be partaking in behavior that generates a reward that this woman consciously values.

The first focus of this research will explore the mate preferences of first year female students illustrating the qualities they look for in a male and what they consider benefits and costs associated with pursuing men with certain characteristics. The second focus will explore both positive and negative experiences fourth year college women have encountered that may alter their perspective in regard to the value of the reward associated with certain behaviors. The third and final focus will be an examination of whether fourth year women alter their behavior and preferences as a result of their past experiences and how this may be more beneficial to them.

\section{Hypotheses}

According to evolutionary theory, it would be adaptive for women in the short term dating environment, such as the college campus, to seek out men who have characteristics that are associated with good genes or high status (Buss, 1989) (These qualities may or may not include athletic ability, maturity, or a membership in a fraternity or on a sports team). Therefore, in the present research women are expected to seek out men who possess these aforementioned characteristics. Through social exchange theory it is also reasonable to believe that if women incur significant costs associated with these men, they will alter their mating strategy and prefer hooking up with men who are less costly and provide more benefits.

On the college campus, a clear discrepancy exists between desired and actual outcomes of a hookup for the woman. By the time the woman reaches her fourth year, it is likely that her preferences will change and she will pursue different characteristics in a mate. Following evolutionary and social exchange theory, through adaptive mechanisms, college women are expected to alter their behavior and pursue mates who possess different characteristics than the men they pursue in their first year. Such characteristics would include those associated with willingness to commit to long term relationships which these fourth year women may come to find more rewarding.

\section{Methods}

\section{Participants}

One hundred ten women ranging in age from 18 - 22 took part in this study. Fifty-five were in their fourth year and 55 were in their first year. Data was collected electronically via an internet survey. Fourth year women were recruited randomly by an email message sent through the university "Webserver". First year women were recruited randomly from the introductory psychology participant pool and received partial course credit for their participation.

\section{Procedure}

Participants were presented with an online link to the survey. 
Once they clicked on the link they received an electronic informed consent form. After giving their consent electronically, they were directed to a survey that consisted of two parts, one which both first and fourth year women completed and a second section that was only available to fourth year women. The survey included demographic questions regarding current relationship status: whether the individual was in a relationship, whether they are currently dating someone at this particular university, and how long they have been dating that person. Additionally, the survey also asked individuals whether or not they participate in short term mating ("hooking up") at this university.

The section of the survey completed by both first and fourth year women asked the participants to rate (on a scale of $1=$ not very important to 5 = very important) how important various qualities are when "selecting a man to hook-up with." The qualities included were attractive, willing to commit, athletic, participation in a fraternity, participation on a sports team, invites you to closed parties, intelligent, trustworthy, has cool friends, and good sense of humor. Women were then asked to distinguish, by answering yes or no, whether or not they considered certain potential outcomes "costs" or "benefits" to hooking up with a senior male student. If they designated these items as "costs" or "benefits," they were asked to rank on a $1=$ not very significant to 5 = very significant scale how significant these items were in making the decision to hookup. Costs items were: dealing with his past relationships, damaging your reputation, his high sexual expectations, his advanced sexual expectations, his different priorities, his higher maturity level, and his lower maturity level. Benefits items were: hooking up increases the chances of entering a relationship, you gain elevated status among female peers, you gain elevated status among your male peers, hooking up increases the chances that the male will eventually enter a relationship, and hooking up increases your ability to attend closed parties. The final question on the first section of the survey given to both groups asked them to "please explain your response."

The next section of the survey was only given to fourth year participants. The women were asked whether or not their perspective on hooking up has changed in the past four years. They were then asked to rank how influential a variety of negative and positive experiences had been on altering their perspective on hooking up with the men at this particular college using a $1=$ not very influential to $5=$ very influential scale. Positive experiences items were: forming friendships and bonds with the male students at this university, getting to know a male at this university on a more personal or familiar level, dating a male at this university, watching the men at this university mature, and other positive experiences. Negative experiences items were: feeling exploited or used by a male student at this university, waiting for a relationship that never happened with a male at this university, being cheated on by a male at this university, Feeling exploited or "used" by a male at this University, being lied to by a male at this university, being embarrassed by a male at this University, and other negative experiences involving a male at this University. The fourth year survey ended with an area in which the participants could enter "any other comments.”

\section{Results}

All data analyses were computed using SPSS. For Phase I, data were analyzed via a 2 (class year) $\times 10$ (\# of preferences listed on questionnaire) mixed model repeated measures ANOVA. An interaction occurred, $F(9,98)=4.80, p<.001$, partial eta squared $=.31$, large effect (Cohen, 1969), that revealed three significant differences in preferences among first and fourth year women. Men's participation on a sports team was significantly more important for the first year women, $t(108)=2.01, p<.047,(M=2.33$, vs. $M=1.89)$. Men's willingness to commit, $t(108)=-2.05, p<.043$, and a good sense of humor, $t(108)=-3.65, p<.0001$, were qualities that fourth year women found significantly more important in a potential mate ( $M=3.41$ vs. $M=3.02$ for willingness to commit for fourth years and first years respectively) and ( $M=4.67$ vs. $M=$ 4.12 for good sense of humor for fourth and first years respectively).

For phase II, a regression was to be computed to determine which costs and benefits predict the change or lack of change in perspective among fourth year students. Of the 55 participants, 89 percent of the fourth year women reported a change in perspective. Five women reported no change in perspective. Four out of the five women who reported no change stated that they did not participate in hooking up. Because every participant that engaged in hooking up, except for the one individual, who reported that her perspective had changed, the regression could not be computed to determine which costs and benefits predict a change or lack of change. Additionally, regressions could not be computed to determine which specific costs and experiences predict this change or lack of change in hookup preferences.

A 2 (class year) $\times 8$ (\# of costs) mixed model repeated measures ANOVA was computed to determine which costs were perceived as most important for first and fourth year women. The ANOVA did not reveal any significant differences among the first and fourth year women.

A Chi square was also computed to determine which costs were perceived as significant among first and fourth year participants. The fourth year group differed from the first year group in that they rated "dealing with a senior male's past relationship(s)," as more costly than the first year group, $X^{2}(102)=$ $6.07, p<.02$, (fourth years $=36$ vs. first years $=25$ ). The fourth year women also differed from the first year women by stating that "dealing with the senior male's lower maturity level," was a significant cost, $X^{2}(101)=9.52, p<.002$, (fourth years $=31$ vs. first years $=16)$. The first year women differed from the fourth year women by rating "a senior male's high sexual expectations," $X^{2}(100)=7.85, p<.009$, (first years $=40$ vs. fourth years = 23) and the senior male's "advanced sexual; experience" as significantly more costly than the fourth year group, $X^{2}(101)=11.32, p<.001$ (first years $=30$ vs. fourth years $=17)$. Chi Square tests were also computed to determine what first and fourth year women found to be significant benefits associated with hooking up with a senior man. The only significant difference in perceived benefits was that first year women perceived "the ability to get you into closed parties" as a significant benefit associated with hooking up with a senior man, $X^{2}(103)=9.50, p<.002$.

A Repeated Measures ANOVA was computed to see which experiences for fourth year women, both positive and negative, were most "influential in altering perspective on hooking up with the males." The ANOVA revealed that the experiences significantly differed, $F(3,46)=9.57, p<.0001$, partial eta square $=.38$, large effect (Cohen, 1969). "Forming a friendship with a male" was the most significant positive experience fol- 
lowed by "dating a male", $(M=3.98, S D=1.60$ and $M=3.86$, $S D=0.20$ for friendship and dating respectively). The most significant negative experience was "feeling exploited or used by a male", $(M=3.40, S D=0.22)$. This was followed by "being lied to by a male" and "being embarrassed by a male", $(M=$ 3.33, $S D=0.22$ and $M=3.33, S D=0.20$ for being lied to and being embarrassed, respectively).

Lastly, a regression was to be computed to see which experiences predict change in preferences and change in willingness to hookup. This was not computed since there was no difference in change in preferences and perspective between individuals who are and individuals who are not in a relationship. Additionally, no difference was found between individuals who are and individuals who are not willing to hookup. Finally, an examination of the frequencies of individuals who report that they hookup revealed no significant difference between first and fourth year women.

\section{Discussion}

The findings were consistent with expectations generated based on evolutionary theory, social exchange theory, and sexual script concepts. As stated in the hypothesis, according to evolutionary theory, it would be adaptive for women in the short term dating environment, such as the college campus, to seek out men who have characteristics that are associated with good genes or high status (Buss, 1989).

Both first and fourth year women selected the same four characteristics as most important in a potential mate. The average woman in both populations found "trustworthy" "good sense of humor" "attractive" and "intelligent" the four most important qualities when "selecting a man to hook up with." These qualities all carry adaptive significance and, through evolutionary theory, can be viewed as indicators of a male's good genes or access to resources. Intelligence may be an indicator of future monetary success and ability to provide resources. Being trustworthy is an indicator that the person may be willing to commit to a long term relationship and remain faithful. A good sense of humor may indicate a personality that is appealing to others. Well liked individuals are often popular and attain high status among friends or within a larger community. Additionally, attractiveness is indicative of good genes (Gangestad \& Simpson, 2000; Buss \& Schmitt, 1993). The women in the present study, regardless of age, find the same characteristics most important which supports evolutionary thinking that postulates universal preferences among different groups of women as adaptive mating preferences.

The next hypothesis predicted a change in perspective between the two groups of women, where fourth year women, due to costs incurred with men in the hook-up environment, would prefer different characteristics in a mate, specifically those associated with willingness to commit to a long term relationship. Although the women in both groups found the same four characteristics most important, a change in preference was apparent. Findings indicated three statistically significant differences in the desired characteristics first and first and fourth year women preferred in a man they wanted to hook up with. Participation on a sports team was significantly more important for the first year women, suggesting that this group may be more concerned with status and good genes. First years may be more concerned with finding a short term mate on an athletic team because, as discussed previously, physical prowess is indicative of good genes that are passed on to potential offspring, increasing the likelihood of survival (Gangestad \& Simpson 2000, Buss \& Schmitt, 1993). Additionally, membership on a team can be a form of status amongst men, and women often employ short term mating for immediate extraction of resources such as status or popularity (Buss \& Schmitt, 1993).

Willingness to commit and a good sense of humor were qualities that fourth year women found significantly more important in a potential mate. Although additional research is need to directly verify this, one can speculate that such characteristics are more important in a long term mate for college women. Temporal contexts are responsible for a preference shift, according to evolutionary theory and according to the solutions to appropriate problems will be employed in various dating contexts. If fourth year women are more concerned with finding long term mates it would be adaptive for them to value cues to “long term provisioning" such as a man's commitment or long term professional success (Buss, 1998). Here, the evolutionary theory provides an explanation regarding adaptive mechanisms adequately suited for each group that explain a difference that exists between the first and fourth year women.

Social exchange theory can be employed to explore other reasons as to why first and fourth year women had these significantly different preferences. This theory suggests that if women incur significant costs associated with certain men, they will alter their mating strategy and prefer hooking up with men who are less costly and provide more benefits.

When asked to rank certain costs and benefits associated with "hooking up with a senior male," the fourth year women differed from the first year women in that they rated "dealing with a senior male's past relationship(s)," as more costly than the first year group. This can be explained by the fact that after spending four years at the same university, senior women know more about the man's past. The fourth year women also differed from the first year women by stating that "dealing with the senior male's lower maturity level,” was a significant cost. The fourth year women often stated in the comments section of the survey that they were ready to move on from college life and felt more mature than the men on campus. Alternatively, the first year women differed from the fourth year women by rating “a senior male's high sexual expectations," as significantly more costly than the fourth year group.

The first year women seemed especially concerned with a damaged reputation, whereas the older women discussed more disappointment associated with a hookup that never turned into a relationship. In the comment section of the survey, one first year woman explained that hooking up with a senior man was costly because of:

"the damage it could do to your reputation when joining a sorority and other things. If you don't meet his high sexual expectations than things will become awkward and abruptly end. Also; if he's on a sports team or in a frat, most likely all of his buddies will know that you're 'reserved' and therefore it may give you a reputation of being a prude."

One can see that this is quite different from one of the many fourth year women who discussed the personal remorse she had experienced and associated with hooking up with the men at her university. She stated that, "I think that one of the biggest problems is that only hooking up allows for girls to get hurt when they expect more out of the relationship and they only get a hookup."

The commentary provided by the fourth year women focused 
more on emotional issues such as feeling used and disappointed when they expected a relationship to emerge from the hookup. This commentary is consistent with the quantitative results of the present research which revealed that "feeling exploited or used" was the most perspective altering experience the women had encountered throughout college. One fourth year woman stated that, "senior males are unwilling to commit and cling to the 'college guy' routine. It is most definitely not worth being in such a relationship; girls are always mistreated." Unlike the first year group, the fourth year women did not list any significant benefits associated with hooking up with the senior class men. In contrast, first year women perceived "the ability to get you into closed parties" as a significant benefit associated with hooking up with a senior class man.

It is not simple enough to state that first year women find hooking up more beneficial than fourth year women. An examination of the frequencies of first and fourth year women revealed no statistically significant difference between groups in willingness to engage in hooking up. Both groups incur significant costs when associated with hooking up and each group seems very aware of what these costs are. Almost all of the fourth year women stated that their perspective on hooking up had changed, but there is no indicator that their willingness to engage in this behavior has diminished. The data suggests that experiences have impacted the way the women perceive the men on campus. Fourth year women rated "forming a friendship with a male" as their most significant positive experience followed by "dating a male." The most significant negative experience was "feeling exploited or used by a male," followed by "being lied to by a male" and "being embarrassed by a male.” Although the data showed a clear change in perspective among these women and recognition that certain experiences have, in fact, altered their perspective, one cannot directly conclude that changed preferences constitute a change in behavior or that women actually pursue different men. Additional research is needed to verify the purported link between attitude and behaviors here.

Research suggests that on the college campus, a clear discrepancy exists between desired and actual outcomes of a hookup for women (Garcia \& Reiber, 2008). Glenn and Marquardt (2002) report an emergence of common themes that women discussed when asked how they felt after hooking up. The highest percentage of women reported feeling "awkward," and it is suggested that these awkward feelings may be a result of confusion as to what actually happened during the interaction and confusion as to what feelings and expectations are appropriate. "Wanting More," was another common theme that was exhibited in the current research. Historical analysis reveals that this phenomenon is new to courtship patterns. In traditional dating societies, the man risked rejection by asking the woman out on another date. Today, women do not know if the men will or will not pursue a relationship. They may feel hurt or disappointed, but blame themselves if they want more out of the hookup. The women constantly stated that they should "know better" than to get disappointed if the man does not pursue a relationship or even acknowledge the woman the next time he sees her (Glenn \& Marquardt, 2002).

The purpose of this research was not to examine women's motivations for hooking up. Past research suggests that one reason women do engage in hooking up is because they are looking for a long term relationship. The findings in this research echo those of Bogle (2008). Bogle's (2008) research provides endless insight into the dynamics between men and women on a college campus. But, for the purpose of the present study, Bogle's (2008) data can be used to help explain the issue of changed perspectives between the first and fourth year college women. Bogle (2008) found that, "when men and women first enter college they seem to be on the same page. The first year is a time when all students can test limits. But, after the first year, things change. Men's and women's goals in the hookup culture diverge; men enjoy the status quo, while women begin to want something more" (Bogle, 2008: p. 97). Bogle (2008) not only examines differences in perspective that exist between men and women, she also provides adequate explanation as to why the woman's perspective changes over time. Bogle (2008) states that those unhappy with the hookup script begin to understand that it is one of the few ways to eventually enter a relationship. Bogle's (2008) explanation supports the findings of this research which show that women "become increasingly relationship oriented after their first year. While many women were still willing to hook up, they wanted hookup encounters to turn into some semblance of a relationship" (Bogle, 2008: p. 97).

The commentary obtained in the present research also supports Bogle (2008) and Glenn and Marqardt's (2002) research. The present research provides an explanation as to why fourth year women at a University engage in hooking up after incurring significant emotional costs. One participant stated that, "While this is not something I have personally experienced; I have seen many lasting relationships form between two seniors in their final year of school. So yes for some I can see the potential benefits associated with hooking up with a senior male that outweigh the costs." It seems likely that fourth year women hope to acquire a long term relationship from their hookups. This may be an explanation as to why their perspective has changed, but their willingness to engage in hookup behavior is the same as the first year group. Additionally, one can see that first and fourth year women seek out different characteristics in a potential man, many of which are evolutionarily adaptive for women to prefer in long term mates. One participant summed up these findings when she stated that:

"For me personally, I am much more selective in who I am even willing to hook up with senior year than I was earlier in college. Therefore, I am hooking up with 'better' guys-nicer, more mature, and I am more comfortable with myself and what I want so am less pressured by the boys/friends. I think many senior males also are more likely to be looking for a relationship, so hooking up at this point has a greater chance of that it would lead to dating or a relationship.”

\section{Conclusion}

The findings in this research are consistent with evolutionary theory, social exchange theory and sexual scripts theory. The characteristics that first and fourth year women value most, intelligent, trustworthy, attractive, and good sense of humor, are all adaptively valuable. The differences that exist in preferences are consistent with the different qualities women value in short term mating contexts compared to the qualities they value in long term environments. These findings suggest that first year women are more concerned with the short term adaptive qualities whereas fourth year women are more concerned with the long term adaptive qualities.

From a social exchange theory perspective, the finding that 
"getting into closed parties" was viewed as a beneficial outcome of hooking up, explains why first year women will continue to pursue a man who can provide this, until getting into a closed party is longer a desired outcome from a hookup. Sexual scripts can also provide some explanation as to why both groups of women continue to engage in the hookup culture although each incurs significant costs associated with the behavior. The fourth year women stated that various experiences have been influential in altering their perspective on this culture. At the same time, the fourth year women still feel as though this behavior is normative and can lead to a relationship.

\section{Limitations}

This study sought to uncover a difference in perspective and behavior among fourth and first year college women. Although differences were observed, the study was cross-sectional and not longitudinal. A cross-sectional design allows one to infer that women have changed their preferences and strategies. But, a longitudinal design would best allow one to actually determine that women have actually changed their preferences and perceptions.

\section{Future Study}

To more directly determine if women change their preferences and perceptions a longitudinal study should be conducted where women are tracked over their four years of college. Additionally, research examining men's preferences and perceptions should be implemented. Research examining men could provide insight as to what men expect in hooking up with a first or fourth year woman. This would allow one to determine whether or not men have different intentions when interacting with each group of women which may explain why the women pursue different characteristics in their first and fourth years of college. Furthermore, it would be informative to examine the differences between first and fourth year men. If men are seemingly disadvantaged in their first year due to having low status, behavior and preferences are likely to shift by the time the man acquires a higher status as a fourth year student.

Additional research with other ethnic groups would increase the scope of the research also. The national sample that was studied by Glenn and Marquardt (2002) revealed that a marked difference existed between white and black students regarding the way they defined the term "hooking up". That research also found that children of divorce are more likely to have hooked up and engage in hookup behavior more frequently. So, utilizetion of a more diverse sample may allow one to see additional patterns and trends related to short term mating strategies.

\section{REFERENCES}

Abelson, R. P. (1981). Psychological status of the script concept.
American Psychologist, 36, 715-729.

doi:10.1037/0003-066X.36.7.715

Bogle, K. A. (2008). Hooking up: Sex, dating and relationships on campus. New York: New York University Press.

Boswell, A. A., \& Spade, J. Z. (1996). Fraternities and collegiate rape culture: Why are some fraternities more dangerous places for women? Gender and Society, 10, 133-147. doi:10.1177/089124396010002003

Buss, D. M. (1989). Sex differences in human mate preferences: Evolutionary hypothesis tested in 37 cultures. Behavioral and Brain Sciences, 12, 1-49. doi:10.1017/S0140525X00023992

Buss, D. M., \& Schmitt, D. P. (1993). Sexual strategies theory: An evolutionary perspective on human mating. Psychological Review, 100, 204-232. doi:10.1037/0033-295X.100.2.204

Buss, D. M. (1998). Sexual strategies theory: Historical origins and current status. The Journal of Sex Research, 35, 19-31. doi:10.1080/00224499809551914

Crawford, C. B., \& Anderson, J. L. (1989). Sociobiology: An environmentalist discipline? American Psychologist, 44, 1449-1459. doi:10.1037/0003-066X.44.12.1449

Costanzo, P. R., \& Shaw, M. E. (1966). Conformity as a function of age level. Child Development, 37, 967-975. doi:10.2307/1126618

Emerson, R. M. (1976). Social exchange theory. Annual Review of Sociology, 2, 335-362. doi:10.1146/annurev.so.02.080176.002003

Flack, W. F., Daubman, K. A., Caron, M., Asadorian, J., D’Aureli, N., Hall, A., Gigliotti, S., Michener, E., \& Wheeler, E. (2007). Risk factors and consequences of unwanted sex among University students. Journal of Interpersonal Violence, 22, 139-157. doi: $10.1177 / 0886260506295354$

Frith, H., \& Kitzinger, C. (2001). Reformulation sexual script theory: Developing a discursive psychology of sexual negotiation. Theory Psychology, 11, 209-232. doi:10.1177/0959354301112004

Gangestad, S. W., \& Simpson, J. A. (2000). The evolution of human mating: Trade-offs and strategic pluralism. Behavioral and Brain Sciences, 23, 573-644. doi:10.1017/S0140525X0000337X

Garcia, J. R., \& Reiber, C. (2008). Hook-up behavior: A biopsychosocial perspective. Journal of Social, Evolutionary, and Cultural Psychology, 192-208.

Glenn, N., \& Marquardt, E. (2001). Hooking up, hanging out, and hoping for Mr. Right. New York: Institute for American Values.

Homans, G. C. (1958). Social behavior as exchange. The American Journal of Sociology, 63, 597-606. doi:10.1086/222355

Kenrick, D. T., Groth, G. E., Trost, M. R., \& Sadalla, E. K. (1993). Integrating evolutionary and social exchange perspectives on relationships: Effects of gender, self-appraisal, and involvement level on mate selection criteria. Journal of Personality and Social Psychology, 64, 951-969. doi:10.1037/0022-3514.64.6.951

Lambert, T. A., Kahn, A. S., \& Apple, K. J. (2003). Pluralistic ignorance and hooking up. The Journal of Sex Research, 40, 129-133. doi:10.1080/00224490309552174

LaPlante, M. N., McCormick, N., \& Brannigan, G. G. (1980). Living the sexual script: College students views of influence in sexual encounters. The Journal of Sex Research, 16, 338-355. doi:10.1080/00224498009551090

O’Sullivan, L. F., \& Byers, E. S. (1992). College students’ incorporation of initiator and restrictor roles in sexual dating interactions. The Journal of Sex Research, 29, 435-446.

doi:10.1080/00224499209551658

Simon, W., \& Gagnon, J. H. (2003). Sexual scripts: Origins, influences and changes. Qualitative Sociology, 26, 491-497. 